Article

\title{
Towards Including Dynamic Vegetation Parameters in the EUMETSAT H SAF ASCAT Soil Moisture Products
}

\author{
Susan C. Steele-Dunne ${ }^{1, *(\mathbb{D})}$, Sebastian Hahn ${ }^{2} \mathbb{D}$, Wolfgang Wagner ${ }^{2} \mathbb{D}$ and Mariette Vreugdenhil ${ }^{2} \mathbb{D}$ \\ 1 Department of Geoscience and Remote Sensing, Delft University of Technology, \\ 2600 GA Delft, The Netherlands \\ 2 Department of Geodesy and Geoinformation, Vienna University of Technology (TU Wien), \\ 1040 Vienna, Austria; sebastian.hahn@geo.tuwien.ac.at (S.H.); Wolfgang.Wagner@geo.tuwien.ac.at (W.W.); \\ mariette.vreugdenhil@geo.tuwien.ac.at (M.V.) \\ * Correspondence: s.c.steele-dunne@tudelft.nl
}

Citation: Steele-Dunne, S.C.; Hahn, S. Wagner, W.; Vreugdenhil, M. Towards Including Dynamic Vegetation Parameters in the EUMETSAT H SAF ASCAT Soil Moisture Products. Remote Sens. 2021, 13, 1463. https:// doi.org/10.3390/rs13081463

Academic Editor: Teodosio Lacava

Received: 28 February 2021

Accepted: 6 April 2021

Published: 10 April 202

Publisher's Note: MDPI stays neutra with regard to jurisdictional claims in published maps and institutional affiliations.

Copyright: (c) 2021 by the authors. Licensee MDPI, Basel, Switzerland. This article is an open access article distributed under the terms and conditions of the Creative Commons Attribution (CC BY) license (https:// creativecommons.org/licenses/by/ $4.0 /)$
Abstract: The TU Wien Soil Moisture Retrieval (TUW SMR) approach is used to produce several operational soil moisture products from the Advanced Scatterometer (ASCAT) on the Metop series of satellites as part of the EUMETSAT Satellite Application Facility on Support to Operational Hydrology and Water Management (H SAF). The incidence angle dependence of backscatter is described by a second-order Taylor polynomial, the coefficients of which are used to normalize ASCAT observations to the reference incidence angle of $40^{\circ}$ and for correcting vegetation effects. Recently, a kernel smoother was developed to estimate the coefficients dynamically, in order to account for interannual variability. In this study, we used the kernel smoother for estimating these coefficients, where we distinguished for the first time between their two uses, meaning that we used a short and fixed window width for the backscatter normalisation while we tested different window widths for optimizing the vegetation correction. In particular, we investigated the impact of using the dynamic vegetation parameters on soil moisture retrieval. We compared soil moisture retrievals based on the dynamic vegetation parameters to those estimated using the current operational approach by examining their agreement, in terms of the Pearson correlation coefficient, unbiased RMSE and bias with respect to in situ soil moisture. Data from the United States Climate Research Network were used to study the influence of climate class and land cover type on performance. The sensitivity to the kernel smoother half-width was also investigated. Results show that estimating the vegetation parameters with the kernel smoother can yield an improvement when there is interannual variability in vegetation due to a trend or a change in the amplitude or timing of the seasonal cycle. However, using the kernel smoother introduces high-frequency variability in the dynamic vegetation parameters, particularly for shorter kernel half-widths.

Keywords: soil moisture; backscatter; radar remote sensing; vegetation; scatterometry; ASCAT

\section{Introduction}

Over the past decade, global-scale soil moisture data products derived from active and passive microwave measurements acquired by polar orbiting Earth observation satellites have become widely available [1]. These include data products derived from the Soil Moisture Active Passive (SMAP) satellite [2], the Soil Moisture and Ocean Salinity (SMOS) mission [3,4] and the Advanced Scatterometer (ASCAT) [5]. The spatial resolution of these microwave soil moisture data products is typically rather coarse, limiting their use in applications such as precision agriculture, landslide prediction or erosion monitoring. Nevertheless, there is an increasing number of applications such as numerical weather prediction or drought monitoring that benefit from using the microwave soil moisture data for model validation and calibration, or by using the satellite data as a direct model input or via data assimilation schemes [5-7]. 
The longest standing operational soil moisture data service rests on ASCAT, an active microwave sensor flown on board a series of three Metop satellites operated by the European Organisation for the Exploitation of Meteorological Satellites (EUMETSAT). The ASCAT soil moisture data products are being generated, distributed and archived by the EUMETSAT Satellite Application Facility on Support to Operational Hydrology and Water Management (H SAF). For the retrieval of surface soil moisture from the ASCAT backscatter measurements, the Vienna University of Technology (TU Wien) Soil Moisture Retrieval (TUW SMR) algorithm has been used. This change detection approach was first developed for ERS-1/2 data [8], and later iterations were applied to ASCAT data [9,10]. The WARP (WAter Retrieval Package) software implementation of TUW SMR forms the basis of the operationally used algorithm to produce the soil moisture products. The Metop ASCAT Surface Soil Moisture (SSM) Climate Data Record (CDR) and Near Real-Time (NRT) products are direct applications of the TU Wien change detection approach using Metop ASCAT backscatter observations. Root zone soil moisture products are obtained by ECMWF by assimilating the Metop ASCAT NRT SSM products into a land surface model.

The relationship between backscattering coefficient as measured by ASCAT and the incidence angle forms an essential element of the TUW SMR algorithm and is described by a second-order Taylor polynomial $[8,11]$. It is used to normalize the ASCAT backscatter measurements to the reference angle $\theta_{r}$ and to account for the influence of vegetation on the sensitivity of normalized backscatter to soil moisture. Relative soil moisture is derived by scaling the normalized backscattering coefficients between the driest and wettest observed soil conditions, respectively.

The slope and curvature coefficients of the Taylor polynomial are estimated from the relation between the backscatter triplet (fore, mid and aft beam) provided by Metop ASCAT [11]. The simultaneous backscatter observations of the three beams allow us to compute an instantaneous backscatter slope, also called "local slope". These rather noisy local slope values are used to estimate the slope and curvature coefficients. The current suite of operational ASCAT-derived soil moisture products use several years of local slope data to produce a seasonal climatology of slope and curvature coefficients [5]. This approach was essential for ERS-1/2 scatterometer data to ensure robust parameter estimates. However, the second set of three fan-beam antennas on ASCAT increased the number of backscatter observations available for the determination of the local slope values. This increased data density makes it possible to determine the slope and curvature dynamically, and hence to account for interannual variations. Melzer [12] proposed a Kernel Smoother (KS) approach to determine the slope and curvature dynamically using the local slope values within some prescribed temporal window. A complete description of the approach was provided by Hahn et al. [11], who performed a cross-comparison of the dynamic slope and curvature values estimated separately from Metop-A and Metop-B to confirm the consistency of the estimated parameters from the two satellites. In addition to demonstrating the robustness of the new KS approach, this study also highlighted the insight to be gained in vegetation dynamics from the interannual variability in slope and curvature coefficients. Subsequent studies by Steele-Dunne et al. [13] and Pfeil et al. [14] related variations in slope and curvature to vegetation dynamics in grasslands and broadleaf deciduous forests.

For the TUW SMR, the implementation of the kernel smoother approach provides a means to distinguish between the two uses of the slope and curvature. A short and fixed window can be used for the backscatter normalization. A fixed window with another length can be used to estimate the slope and curvature needed to account for the effect of vegetation. The use of the KS to estimate this slope and curvature allows us to take interannual variability in the effect of vegetation into account. Hence, the slope and curvature estimated with the KS for the vegetation correction are here referred to as the Dynamic Vegetation Parameters (DVPs).

In this study, we examined the impact of using the DVPs in the TU Wien Soil Moisture Retrieval (TUW SMR) algorithm. Here, we compared the performance of the soil moisture retrieval algorithm based on DVP to the current implementation using climatological 
values, identified limitations of the new approach and suggested measures to be taken in order to implement it in the operational soil moisture retrieval algorithm.

\section{Materials and Methods}

\subsection{TU Wien Soil Moisture Retrieval}

Backscatter from the land surface is influenced by factors such as soil composition, surface roughness and land cover type, which are assumed to be temporally stable at the scatterometer measurement scale $(25-50 \mathrm{~km})$, as well as the combined influence of vegetation and soil moisture dynamics.

In the TUW SMR, the backscattering coefficient $\sigma^{\circ}$ in decibels (dB) is assumed to be linearly related to surface soil moisture. Soil moisture in the surface layer at time $t$ is given by:

$$
\Theta_{s}(t)=\frac{\sigma^{\circ}\left(\theta_{r}, t\right)-\sigma_{d}^{\circ}\left(\theta_{r}, t\right)}{\sigma_{w}^{\circ}\left(\theta_{r}, t\right)-\sigma_{d}^{\circ}\left(\theta_{r}, t\right)}
$$

where $\sigma^{\circ}, \sigma_{w}^{\circ}$ and $\sigma_{d}^{\circ}$ are the backscattering coefficient and the wet and dry references (in $\mathrm{dB})$ at the reference incidence angle $\theta_{r}$ at time $t$. The so-called "dry reference", on a given date, represents the lower limit of the range within which the backscattering coefficient varies due to soil moisture. The upper limit ("wet reference") reflects the highest value of backscattering coefficient observed over time at a certain location. They are given by [15]:

$$
\begin{gathered}
\sigma_{w}^{\circ}(t)=C_{w}-\sigma^{\prime}(t)\left(\theta_{w}-\theta_{r}\right)-\frac{1}{2} \sigma^{\prime \prime}(t)\left(\theta_{w}-\theta_{r}\right)^{2} \\
\sigma_{d}^{\circ}(t)=C_{d}-\sigma^{\prime}(t)\left(\theta_{d}-\theta_{r}\right)-\frac{1}{2} \sigma^{\prime \prime}(t)\left(\theta_{d}-\theta_{r}\right)^{2}
\end{gathered}
$$

where $C_{w}$ and $C_{d}$ are two constants that set the overall strength of backscatter during wet and dry soil moisture conditions and $\theta_{w}$ and $\theta_{d}$ are the so-called cross-over angles where backscatter is assumed to be unaffected by vegetation phenology. The two variables $\sigma^{\prime}(t)$ and $\sigma^{\prime \prime}(t)$ are the slope and curvature that characterise the incidence angle behaviour of the backscattering coefficient $\sigma^{\circ}(\theta)$ at any point in time $t$.

Given that the curve $\sigma^{\circ}(\theta)$ reflects the relative magnitude of soil surface backscatter and volume scattering from the vegetation, $\sigma^{\prime}(t)$ and $\sigma^{\prime \prime}(t)$ capture dynamic vegetation effects. Hence, we refer to them here as Dynamic Vegetation Parameters (DVPs). Their principal effect is to change the sensitivity of $\sigma^{\circ}$ to soil moisture over time depending on the vegetation state:

$$
\Delta \sigma^{\circ}(t)=\sigma_{w}^{\circ}(t)-\sigma_{d}^{\circ}(t)=\Delta C-\sigma^{\prime}(t)\left(\theta_{w}-\theta_{d}\right)-\frac{1}{2} \sigma^{\prime \prime}(t)\left(\theta_{w}^{2}-\theta_{d}^{2}-2 \theta_{r}^{2}\left(\theta_{w}-\theta_{d}\right)\right)
$$

with $\Delta C=C_{w}-C_{d}$. As the slope becomes less steep with increasing vegetation biomass, the effect of vegetation growth is to reduce the sensitivity $\Delta \sigma^{\circ}$ (Figure 1). This reduction in sensitivity was related by Vreugdenhil et al. [16] to the vegetation optical depth $\tau$ using:

$$
\Delta \sigma^{\circ}=\Delta \sigma_{\text {soil }}^{\circ} \exp ^{\frac{2 \tau(t)}{\cos \theta}}
$$

In other words, changes in $\sigma^{\prime}(t)$ and $\sigma^{\prime \prime}(t)$ are interpreted as changes in the vegetation optical depth. However, as recently shown by [14], vegetation structure may also impact the slope, notably at shorter time scales. Unfortunately, this is detrimental to the TUW SMR method as such effects would wrongly change the sensitivity $\Delta \sigma^{\circ}$. At present, the importance of changes in vegetation structure and other environmental effects on $\sigma^{\prime}(t)$ and $\sigma^{\prime \prime}(t)$ are not sufficiently understood. This study is a first attempt to quantify their impact on the soil moisture retrievals. 


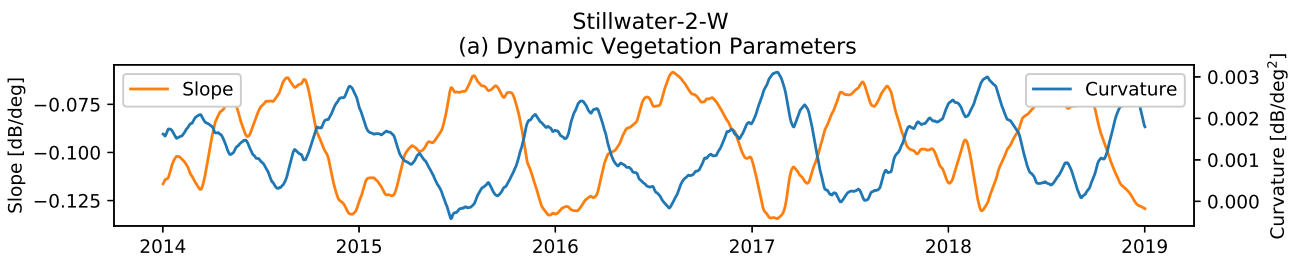

(b) Sensitivity to soil moisture

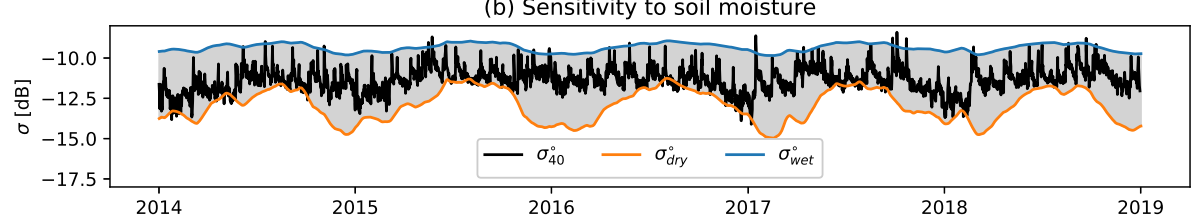

Figure 1. Five years of ASCAT data at Stillwater, Oklahoma $\left(36.1^{\circ} \mathrm{N} 97.1^{\circ} \mathrm{W}\right)$, to illustrate the estimated variations in (a) slope and curvature and (b) dry and wet references. The difference between the wet and dry reference, $\Delta \sigma^{\circ}$ indicated in grey, is a measure of the sensitivity of backscatter $\left(\sigma_{40}^{\circ}\right)$ to soil moisture.

Data from ERS have been used to demonstrate that the slope $\left(\sigma^{\prime}\right)$ depends linearly on the incidence angle $(\theta)[8]$ :

$$
\sigma^{\prime}(\theta)=\sigma^{\prime}\left(\theta_{r}\right)+\sigma^{\prime \prime}\left(\theta_{r}\right) \cdot\left(\theta-\theta_{r}\right) \quad[\mathrm{dB} / \mathrm{deg}]
$$

where $\theta_{r}$ is a reference incidence angle, set to $40^{\circ}$ here. The dependence of the backscattering coefficient on the incidence angle can therefore be described as a second-order polynomial:

$$
\sigma^{\circ}(\theta)=\sigma^{\circ}\left(\theta_{r}\right)+\sigma^{\prime}\left(\theta_{r}\right) \cdot\left(\theta-\theta_{r}\right)+\frac{1}{2} \sigma^{\prime \prime}\left(\theta_{r}\right) \cdot\left(\theta-\theta_{r}\right)^{2} \quad[\mathrm{~dB}]
$$

Given the slope $\left(\sigma^{\prime}\left(\theta_{r}\right)\right)$ and curvature $\left(\sigma^{\prime \prime}\left(\theta_{r}\right)\right)$, the scatterometer measurements at any incidence angle can be extrapolated to the reference angle of $\theta_{r}$ :

$$
\sigma^{\circ}\left(\theta_{r}\right)=\sigma^{\circ}(\theta)-\sigma^{\prime}\left(\theta_{r}\right) \cdot\left(\theta-\theta_{r}\right)-\frac{1}{2} \sigma^{\prime \prime}\left(\theta_{r}\right) \cdot\left(\theta-\theta_{r}\right)^{2}
$$

Re-arranging this expression provides a means to extrapolate the backscatter to any incidence angle if the slope, curvature and $\sigma^{\circ}\left(\theta_{r}\right)$ are known.

The slope and curvature coefficients of the Taylor polynomial are estimated by exploiting ASCAT's unique viewing geometry. ASCAT is a fixed fan-beam scatterometer, with two sets of three sideways-looking antennas, each illuminating a $550 \mathrm{~km}$ wide swath on either side of the satellite track. The three antennas on each side are oriented at $45^{\circ}$ (fore), $90^{\circ}$ (mid) and $135^{\circ}$ (aft) to the satellite track. The incidence angle range of the fore and aft antennas is $34-65^{\circ}$, while the mid antenna covers $25-55^{\circ}$. Each location on the surface is observed with three slightly asynchronous, independent backscatter measurements with three independent viewing directions. These "backscatter triplets" are used to compute an instantaneous backscatter slope, also called the "local slope":

$$
\sigma^{\prime}\left(\frac{\theta_{\text {mid }}-\theta_{a / f}}{2}\right)=\frac{\sigma_{\text {mid }}^{\circ}\left(\theta_{\text {mid }}\right)-\sigma_{a / f}^{\circ}\left(\theta_{a / f}\right)}{\theta_{\text {mid }}-\theta_{a / f}} \quad[\mathrm{~dB} / \mathrm{deg}]
$$

where mid indicates the mid beam antenna and the subscript $a / f$ indicates whether this local slope value is using the aft beam or fore beam antenna.

A large number of local slope values must be combined to account for the substantial noise in individual values [17] and to ensure that the slope is sampled across a wide range of incidence angles. The method used to combine many local slope values has evolved to exploit the growing data record and the improved data density of ASCAT observations [11]. 
Operational ASCAT-derived soil moisture products currently distributed by EUMETSAT H SAF [18] combine several years of local slope data to produce a seasonal climatology of slope and curvature coefficients $[10,19]$. This approach was particularly important in the ERS-1/2 era to ensure robust parameter estimates. The increase in data density due to the second set of three fan-beam antennas on ASCAT means that it is now possible to determine the slope and curvature dynamically using the Kernel Smoother (KS) approach proposed by Melzer [12] and explained in detail by Hahn et al. [11]. The slope and curvature on day $d$ are estimated by combining all local slope values in the interval $\left|\left(d-d_{0}\right) / \lambda\right| \leq 1$ in a linear regression. The local slope values are weighted so that they decrease with distance from the date of interest $d_{0}$ according to an Epanechnikov kernel [20]:

$$
\begin{gathered}
k\left(d_{0}, d\right)=D \frac{d-d_{0}}{\lambda} \\
D(t)= \begin{cases}\frac{3}{4} \cdot\left(1-t^{2}\right), & \text { if }|t| \leq 1 \\
0, & \text { otherwise }\end{cases}
\end{gathered}
$$

The weights sum to one, by definition, and are finite in the range $[-\lambda, \lambda]$.

The kernel half-width $\lambda=21$ was considered by Melzer et al. [12] to provide a reasonable balance between bias and variance in the estimate. In a subsequent global analysis, Hahn et al. [11] estimated the dynamic slope and curvature separately from Metop-A and Metop-B. The consistency of the independent estimates in a cross-comparison suggests that the estimation approach is robust. Furthermore, time series plots at several locations, as well as Hovmöller diagrams were used to demonstrate that this approach captured plausible seasonal and interannual variations in vegetated areas.

\subsection{Study Domain}

In situ soil moisture observations from the United States Climate Research Network (USCRN) [21] were used in this study to ensure some diversity in terms of climate type and land cover. Data for the 109 USCRN stations were accessed through the International Soil Moisture Network (ISMN) [22]. The ASCAT grid points associated with these stations span eight ESA CCI Land Cover Climate Classes (Figure 2) and fourteen Köppen-Geiger Climate Classes (Figure 3). Almost half of the stations are in grassland areas, with the remainder in footprints dominated by shrubland, tree cover and rainfed cropland. There are four main Köppen-Geiger Climate Classes; humid subtropical climate (Cfa), cold semi-arid climate (BSk), continental climate with a hot summer (Dfa) and continental climate with a warm summer $(\mathrm{Dfb})$. In this study, results are presented based on 85 stations. Several desert shrubland locations in the Western U.S. were excluded due to suspected enhanced volumetric scattering [23]. In addition, climate or land cover classes with fewer than five stations were omitted. For example, this excluded stations within an ASCAT footprint classed as water or flooded with brackish water (e.g., The Everglades, Florida). 


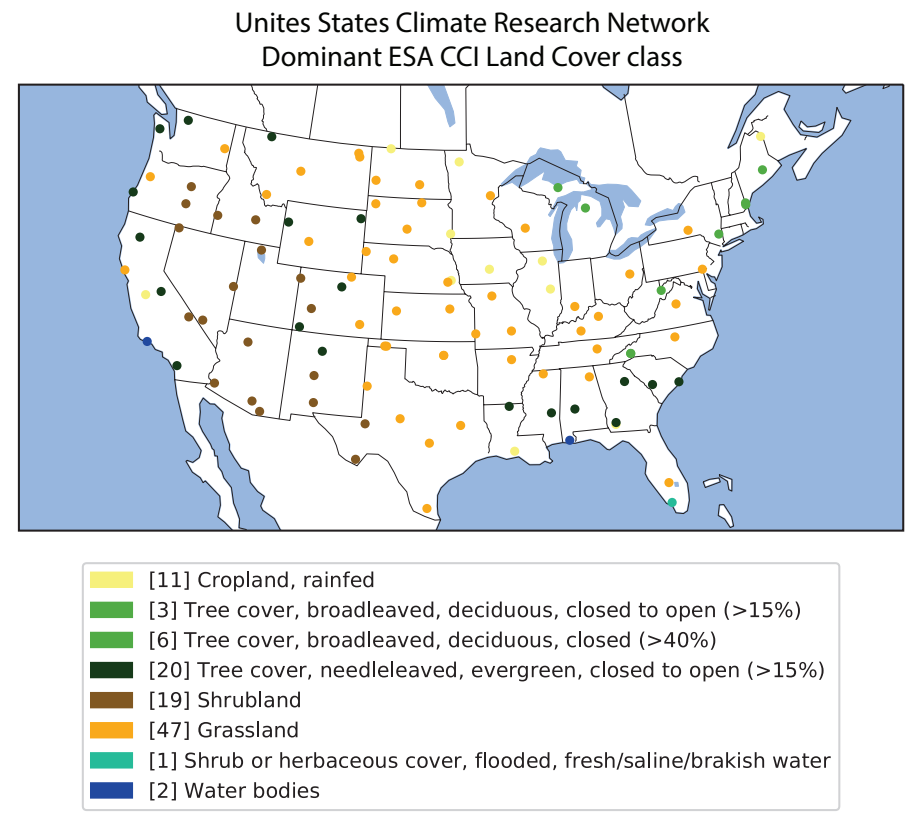

Figure 2. United States Climate Research Network (USCRN) Soil Moisture Stations, coloured by ESA CCI Land Cover Class. The numbers in square brackets indicate the number of occurrences of each type.

United States Climate Research Network KG Climate Class

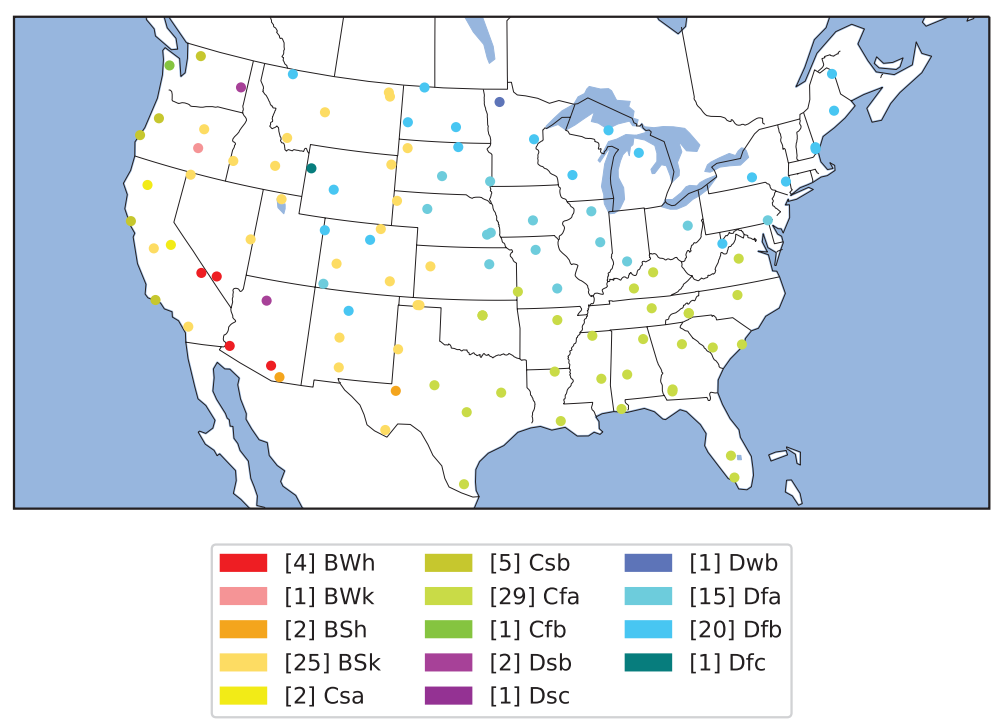

Figure 3. USCRN Soil Moisture Stations, coloured by Köppen-Geiger (KG) Climate Class. The numbers in square brackets indicate the number of occurrences of each type.

\subsection{ASCAT Processing}

Ten years of Metop-A ASCAT SZR Level 1b backscatter data, using the $12.5 \mathrm{~km}$ swath grid sampling, were obtained from the EUMETSAT Data Centre. Standard pre-processing steps were performed: (1) the backscatter observations were resampled to a fixed Earth grid using a Hamming window function and the procedure described by Naeimi et al. [10]; (2) the empirical approach of Bartalis et al. [24] was used to account for azimuthal effects. Backscatter triplets were used to calculate the local slope using Equation (9).

In the climatology case, the vegetation parameters were determined using the current operational approach of Naeimi et al. [10]. For the dynamic vegetation parameters, the 
methodology proposed by Melzer [12] was used to estimate the vegetation parameters from these local slopes. In all cases, a kernel with $\lambda=11$ days was used to estimate the slope and curvature required to normalize the backscatter. For the wet and dry reference calculation, the default value of $\lambda=21$ days was based on the analysis of Melzer [12]. To investigate the influence of the kernel half-width on the estimated soil moisture, the vegetation parameters were also determined using a shorter $(\lambda=11$ days $)$ and longer $(\lambda=31$ days) window size.

\subsection{Performance Assessment}

Each implementation of the TUW SMR approach was applied at the grid points colocated with the in situ soil moisture stations of the USCRN network. Data for these stations were obtained from the ISMN [22], and temporal matching was applied at a daily level. The estimated soil moisture values were compared to those reported for surface soil moisture $(0-5 \mathrm{~cm})$ at each station. Local slopes obtained over frozen or snow-covered soil introduced artefacts into the dry reference that were unrelated to vegetation, resulting in an error in the sensitivity to soil moisture, and hence soil moisture itself. Dates on which the soil was frozen or snow-covered were identified using ERA5 soil temperature and snow depth data. To ensure that a consistent number of data points were considered in each scenario, the snow / frozen soil mask was determined for the longest half-width $(\lambda=31$ days) and applied to all time series prior to the calculation of the performance metrics. Results were evaluated using the Pearson correlation coefficient, unbiased root mean squared difference and bias [25].

\section{Results}

\subsection{Climatology}

Figure 4 shows the performance metrics using the current operational approach for the 85 USCRN stations considered here. The median Pearson correlation coefficient was 0.58 with $90 \%$ of the values between 0.29 and 0.79 , respectively. Values were generally higher in the Central U.S. and lower at the more arid stations in the West. The median unbiased Root Mean Squared Difference (ubRMSD) was $0.09 \%$, with $90 \%$ of values between 0.06 and 0.13 . The median bias was $0.01 \%$ with $90 \%$ of values between $-0.13 \%$ and $0.10 \%$. Negative values were more common in the West, with more positive values in the East, particularly the Northeast.
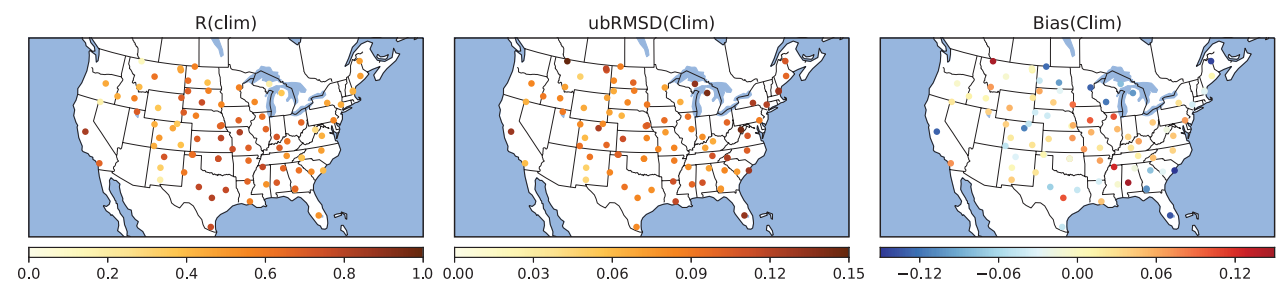

Figure 4. Pearson correlation coefficient (R), unbiased RMSD and bias between in situ soil moisture and soil moisture retrieved using vegetation parameters derived from climatological (clim) values.

Figure 5 shows how the soil moisture performance metrics related to the dominant land cover $(\mathrm{a}-\mathrm{c})$ and climate classes $(\mathrm{d}-\mathrm{f})$. The best and most consistent performance was in grasslands in which $\mathrm{R}$ was generally greater than 0.5 , ubRMSD was at the lower end of the range observed and the median bias was close to zero. The same was true for rainfed cropland ( $\mathrm{LC}=10)$, though it is noteworthy that the range in bias was large. Performance was notably good over evergreen forests: $R$ and ubRMSD were comparable to those observed in grassland and rainfed cropland, and the median bias was close to zero. Performance was relatively poor in broadleaf deciduous forest where $\mathrm{R}$ was low and ubRMSD was higher than in the other land classes. In terms of climate class, it seemed that performance was best in Dfa (humid continental climate with hot summers). This 
corresponds to a mixture of land cover types in the Central to Northeastern U.S. The worst performance was in Dfb (humid continental climate with warm summers). The stark difference between these two climate subtypes was due to the fact that many of the stations in the Dfb climate class are in grid points with a large fraction of broadleaf deciduous forest.
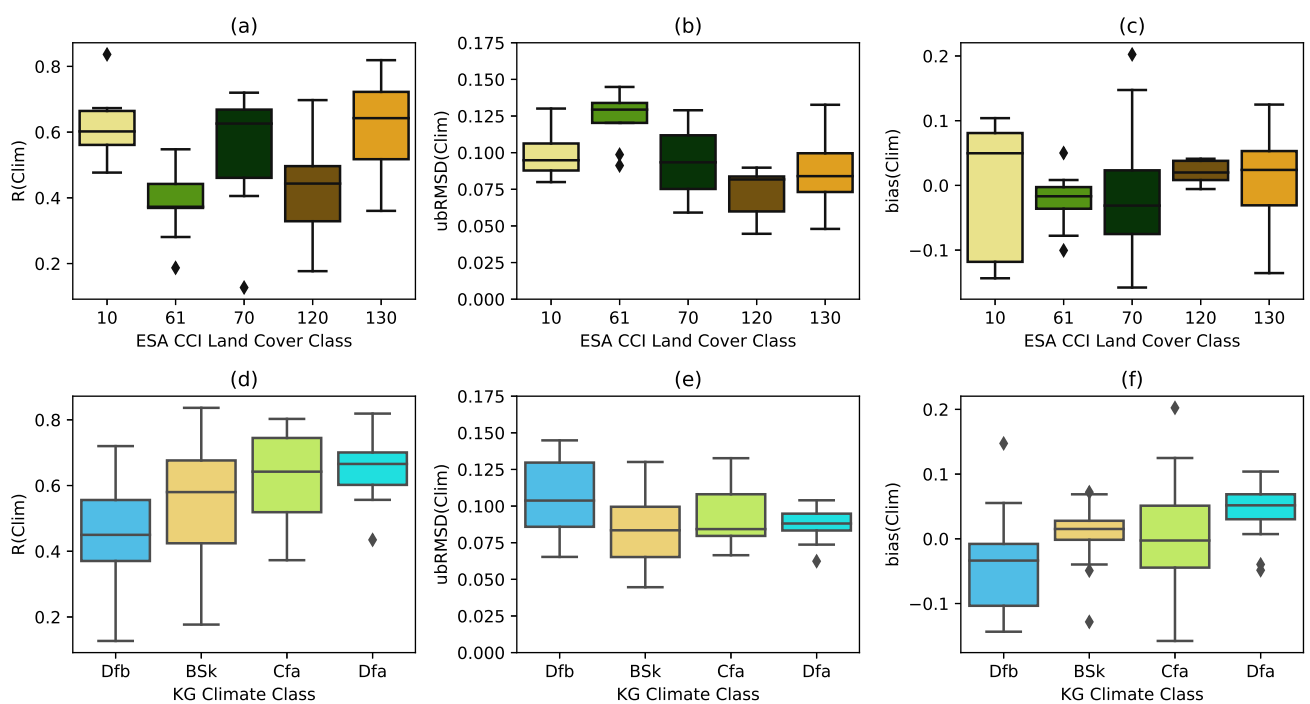

Figure 5. Box plots of the Pearson correlation coefficient (R), unbiased RMSD and bias between in situ soil moisture and soil moisture retrieved using vegetation parameters derived from climatological values, sorted by ESA CCI Land Cover Class $(\mathbf{a}-\mathbf{c})$ and Köppen-Geiger Climate Class $(\mathbf{d}-\mathbf{f})$. The box extends from the lower to upper quartile values of the data, with a line at the median. The lower whisker is at the lowest datum above $\mathrm{Q} 1-1.5 *(\mathrm{Q} 3-\mathrm{Q} 1)$ and the upper whisker at the highest datum below $\mathrm{Q} 3+1.5 *(\mathrm{Q} 3-\mathrm{Q} 1)$, where $\mathrm{Q} 1$ and $\mathrm{Q} 3$ are the first and third quartiles. Outliers are indicated as diamonds.

\subsection{Including Dynamic Vegetation Parameters}

Figure 6 maps the difference in performance metrics when the dynamic vegetation parameters ( $\lambda=21$ days) were used to estimate the sensitivity, compared to using climatological values. For the 85 stations considered, the median change in $\mathrm{R}$ was 0.00 . While some increase in R was observed in the West, $\mathrm{R}$ was consistently lower in the Central U.S. Furthermore, introducing DVPs led to a median increase in both ubRMSD and bias of $0.02 \%$ (volumetric soil moisture). The bias was generally lower in the West, but higher in the East and North.
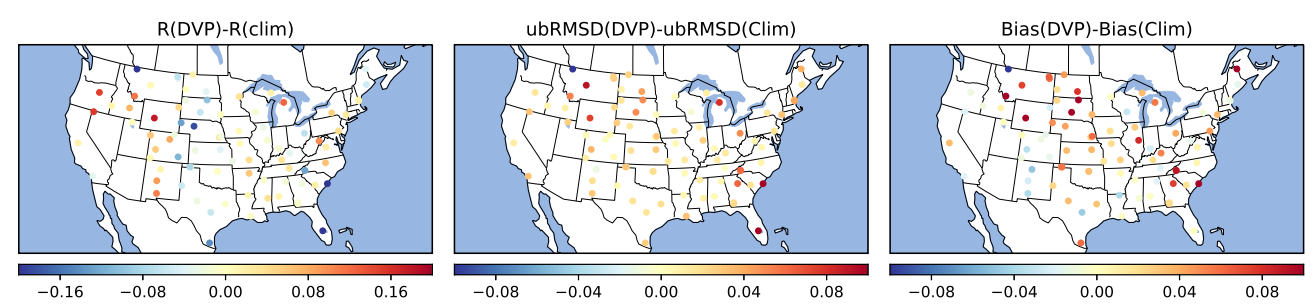

Figure 6. Difference in the Pearson correlation coefficient (R), unbiased RMSD and bias between in situ soil moisture and soil moisture retrieved using vegetation parameters derived using Dynamic Vegetation Parameters (DVPs) $(\mathrm{hw}=21)$ and those derived from climatological values.

Figure 7 provides some insight into the impact of the DVPs as a function of land cover and climate class. The median improvement in $\mathrm{R}$ was close to zero in all land cover types apart from shrublands. Both the ubRMSD and bias were higher using DVPs than climatology in all cover types. The impact on bias was particularly large in rainfed 
cropland and grasslands. The range of impact, in the sense of a change in the performance metric, was consistently largest for the grasslands. The degree to which high-frequency variations were introduced by DVPs clearly varied considerably among grassland sites. From Figure $7 \mathrm{~d}-\mathrm{f}$, the results mostly indicated that the widest variation in terms of impact was in BSk (cold semi-arid climates), i.e., in the West, which included grasslands and shrublands. The impact was also highly variable in the Dfb class, which contained many of the forest cover types.
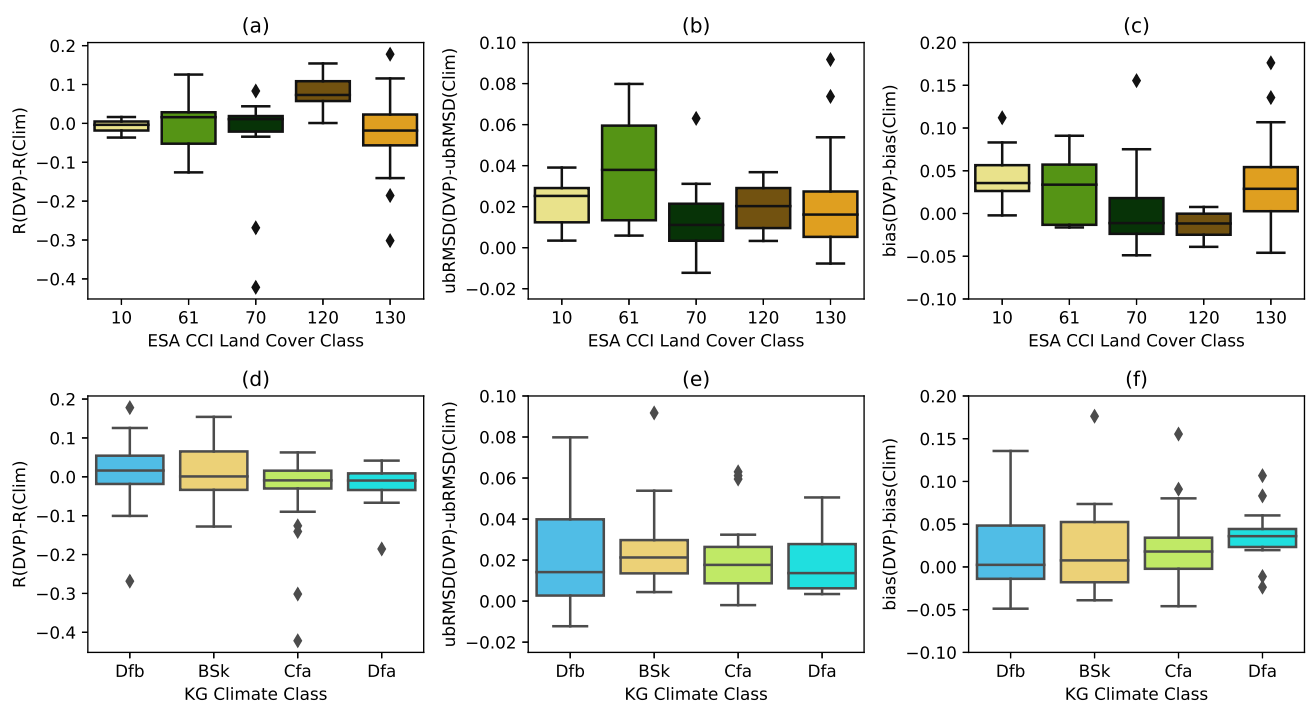

Figure 7. Box plot of the difference in the Pearson correlation coefficient (R), unbiased RMSD and bias between in situ soil moisture and soil moisture retrieved using vegetation parameters derived using dynamic vegetation parameters $(\lambda=21$ days) and those derived from climatological values. Data are binned by ESA CCI Land Cover Class (a-c) and Köppen-Geiger Climate Class (d-f). The box extends from the lower to upper quartile values of the data, with a line at the median. The lower whisker is at the lowest datum above Q1 $-1.5 *(\mathrm{Q} 3-\mathrm{Q} 1)$ and the upper whisker at the highest datum below $\mathrm{Q} 3+1.5 *(\mathrm{Q} 3-\mathrm{Q} 1)$, where $\mathrm{Q} 1$ and $\mathrm{Q} 3$ are the first and third quartiles. Outliers are indicated as diamonds.

Figure 8 shows the dry reference for three stations to illustrate the impact of implementing DVPs compared to using the climatological values. At Chillicothe (Figure 8a), the seasonal cycle in dry reference was strong, and there was little interannual variability. The Pearson correlation coefficient using climatological vegetation parameters was already 0.82 . Accounting for interannual variability in the slope and curvature had barely any effect on the dry reference, so implementing DVPs had a limited effect on the soil moisture retrieval performance. At Bowling Green (Figure 8b), implementing DVPs revealed a decreasing trend in the maximum dry reference, which was obviously not taken into account in the climatological values. The implementation of DVP resulted in an increase of 0.04 in R. Data from Lander (Figure 8c) showed that the implementation of DVPs sometimes yielded an apparently substantial increase in R. While there certainly did appear to be interannual variability in the dry reference, it is important to note that there were relatively few days without snow/frozen soil. Hence, the statistics at this station were based on too few data to be reliable. 
(a) Chillicothe-22-ENE, ESA LC: 130

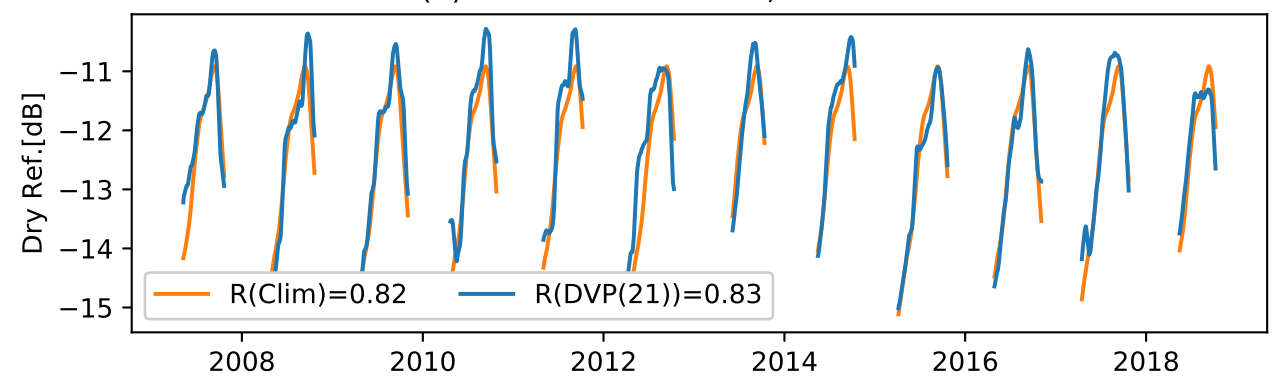

(b) Bowling-Green-21-NNE, ESA LC: 130

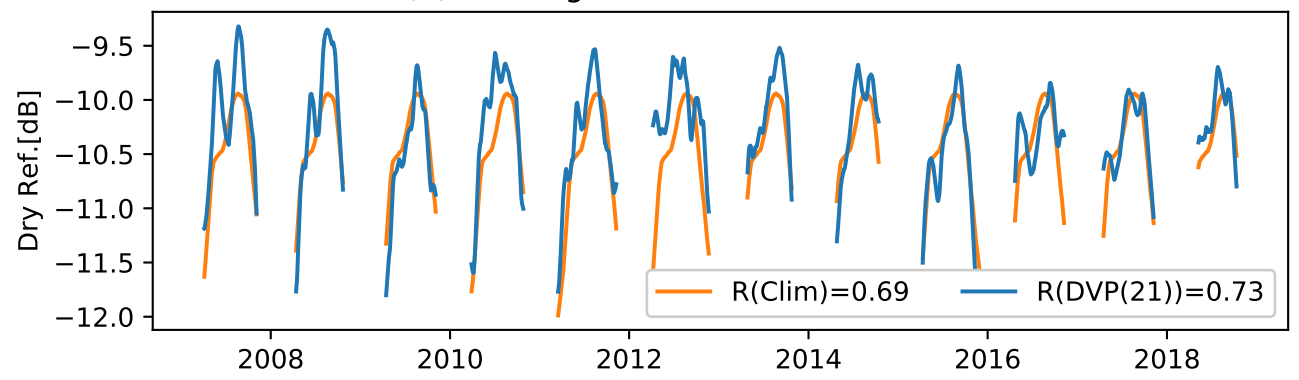

(c) Lander-11-SSE, ESA LC: 130

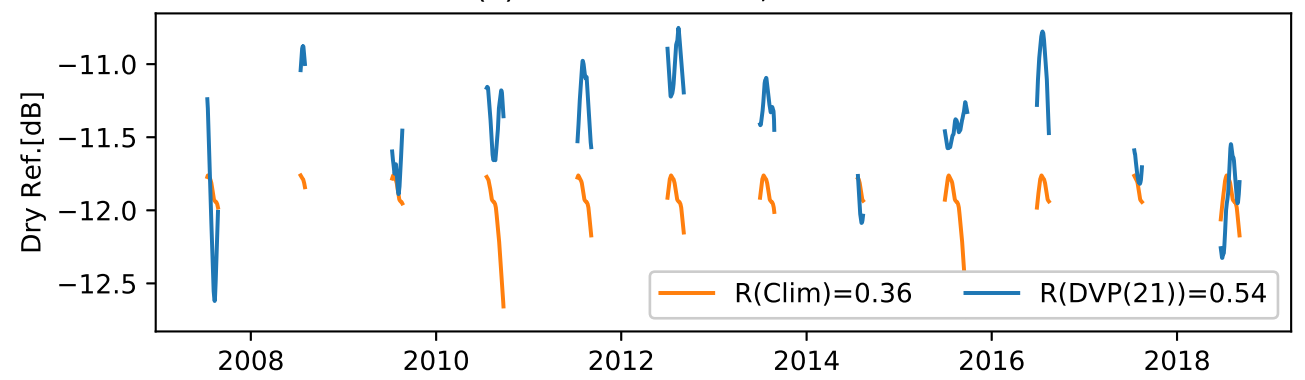

Figure 8. Comparison of the dry reference estimated using vegetation parameters from climatology and dynamic vegetation parameters at three stations that indicate modest to significant improvement in R when DVPs are used. Results are presented for (a) Chillecothe (b) Bowling Green and (c) Lander stations.

\subsection{Influence of the Kernel Half-Width}

Figure 9 shows a single year of data from Stillwater, Oklahoma, for each of the TUW SMR implementations to illustrate the influence of the the kernel smoother and the kernel half-width $\lambda$ on the vegetation parameters (Figure $9 b, c$ ) and dry reference (Figure 9d). Stillwater is a grassland site with a humid, subtropical climate (Cfa). The seasonal cycle in vegetation cover is reflected in the variations of slope and curvature [13]. The dry reference estimated using the climatological vegetation parameters had a smooth seasonal cycle with a maximum during the Northern Hemisphere summer. Variations in wet reference were similar in sign, but much smaller in magnitude (Figure 1). Hence, the sensitivity $\left(\Delta \sigma^{\circ}(t)=\sigma_{w}^{\circ}-\sigma_{d}^{\circ}\right)$ to soil moisture was greatest during the winter. Note, for example, that the normalized backscatter $\left(\sigma_{40}^{\circ}\right)$ was much higher than the dry reference when the in situ soil moisture was high during the winter. During the summer months, in situ soil moisture also varied considerably, but the range within which it could vary (i.e., $\Delta \sigma^{\circ}(t)$ was much smaller. The slope, curvature and dry reference estimated using the DVP with $\lambda=11$ days exhibited high-frequency variations superimposed on the background seasonal cycle. Increasing the half-width meant averaging over more local slope values, mitigating the influence of individual events. Smoothing these features out yielded a seasonal cycle in the vegetation parameters more similar to those from the climatological values. Increasing the kernel length smoothed out most of the features 
during the winter months. However, there were some features (e.g., in May and October) for which increasing the half-width to $\lambda=31$ days resulted in further smoothing, bringing the parameter estimates closer to the estimates from climatology. The degree to which additional smoothing should be applied is discussed in the next section.
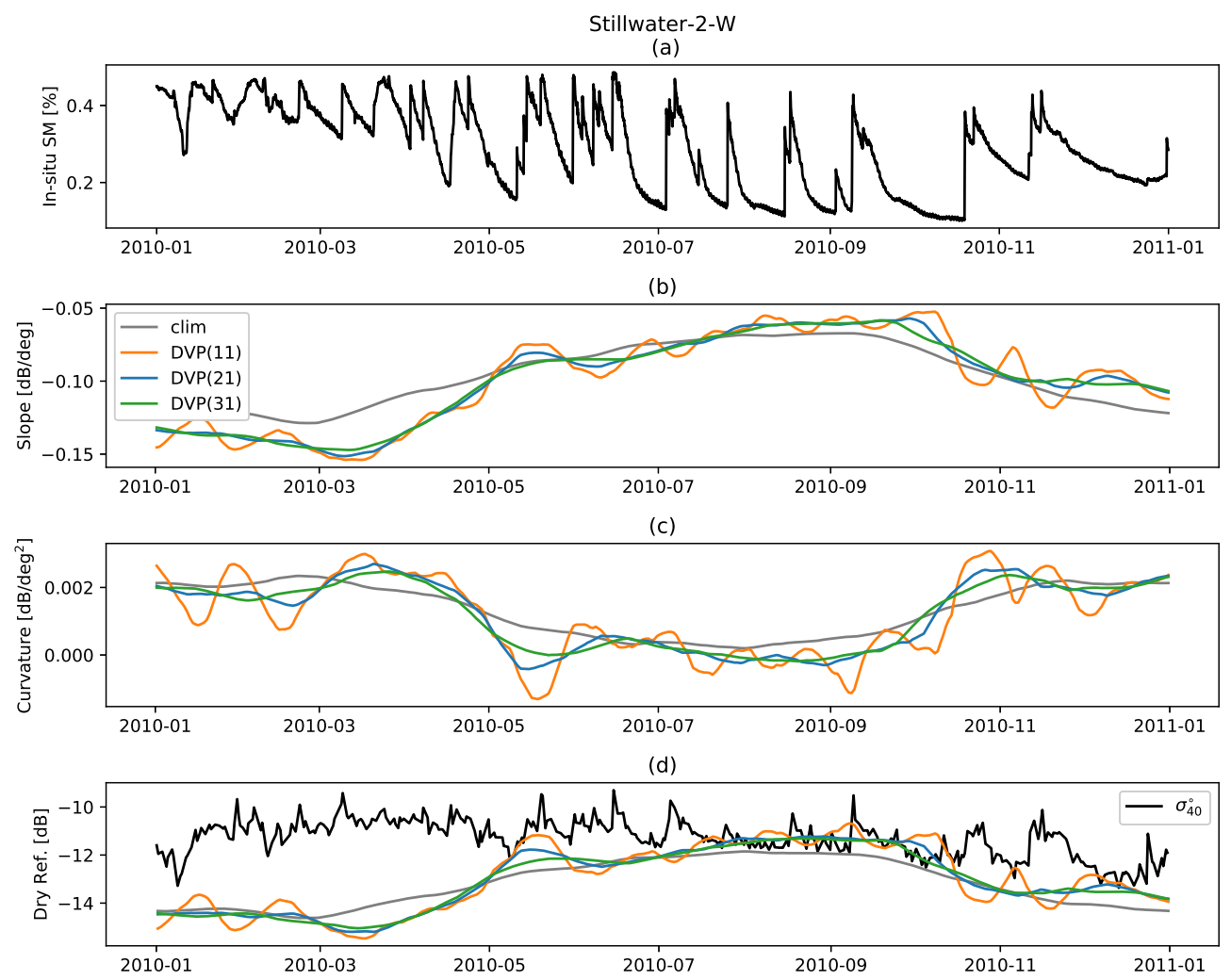

Figure 9. (a-d) The influence of the kernel half-width (in days 11: orange, 21: blue or 31: green) on the dynamic vegetation parameters and estimated dry reference at Stillwater, Oklahoma, in 2010.

Figure 10 shows the impact of changing the kernel half-width on the soil moisture performance metrics for all stations. In general, using a shorter kernel led to a decrease in $\mathrm{R}$, an increase in ubRMSD and an increase in bias, i.e., a detrimental effect on performance. As shown in Figure 9, this can be attributed to the introduction of high-frequency variations when few local slope values were averaged. Increasing the kernel length generally led to a lower Pearson correlation coefficient in the dry Western areas, but an increase across the Central and Eastern U.S. It also reduced the ubRMSD and bias. It seems that a short kernel length was adequate in the dry, shrubland areas in the West. In the more humid areas with more vegetation, a longer kernel generally led to an improved performance.

Regardless of kernel length, DVPs still often failed to perform as well as the climatological vegetation parameters. This is illustrated in Figure 11, which summarizes the impact of using the DVP compared to the climatology for all 85 stations. For each of the metrics, it is clear that increasing $\lambda$ was beneficial. Increasing $\lambda$ from 11 to 31 changed the median values of $\Delta R$ from -0.018 (worse than climatology) to 0.0055 (slightly better than climatology) and reduced the median $\triangle u b R M S D$ from 0.046 to 0.011 and the median $\triangle$ bias from 0.046 to 0.005 . Nonetheless, it is clear that even with $\lambda$ of 31 , the soil moisture estimates using DVPs were worse than those estimated using vegetation parameters from climatology in terms of ubRMSD and bias. In terms of $R$, the results were more evenly mixed. 

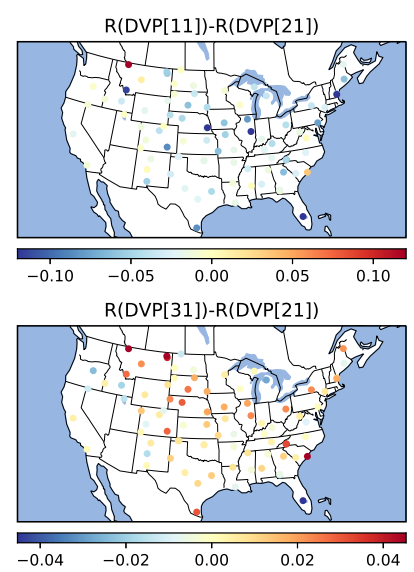
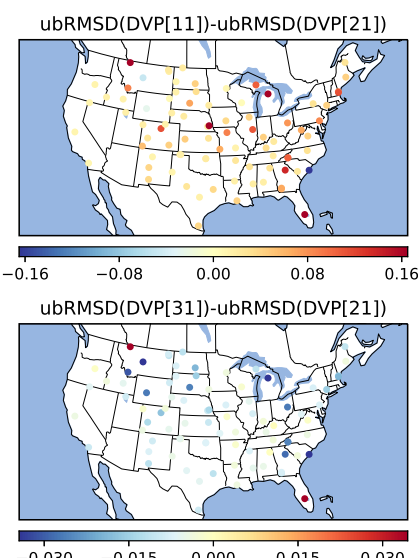

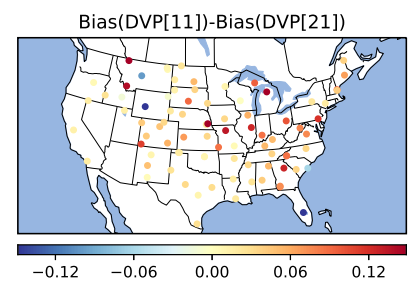

$\operatorname{Bias}(\mathrm{DVP}[31])-\operatorname{Bias}(\mathrm{DVP}[21])$

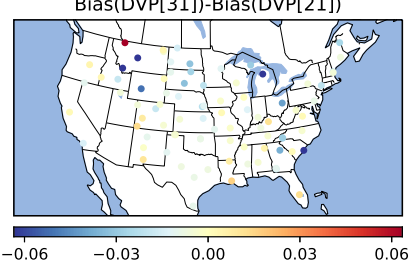

Figure 10. Impact of the kernel half-width $(\lambda)$ on R, ubRMSD and bias between in situ and soil moisture retrieved using dynamic vegetation parameters. Half-widths of $\lambda=11$ and $\lambda=31$ are compared to the default value of $\lambda=21$ in the top and bottom rows, respectively
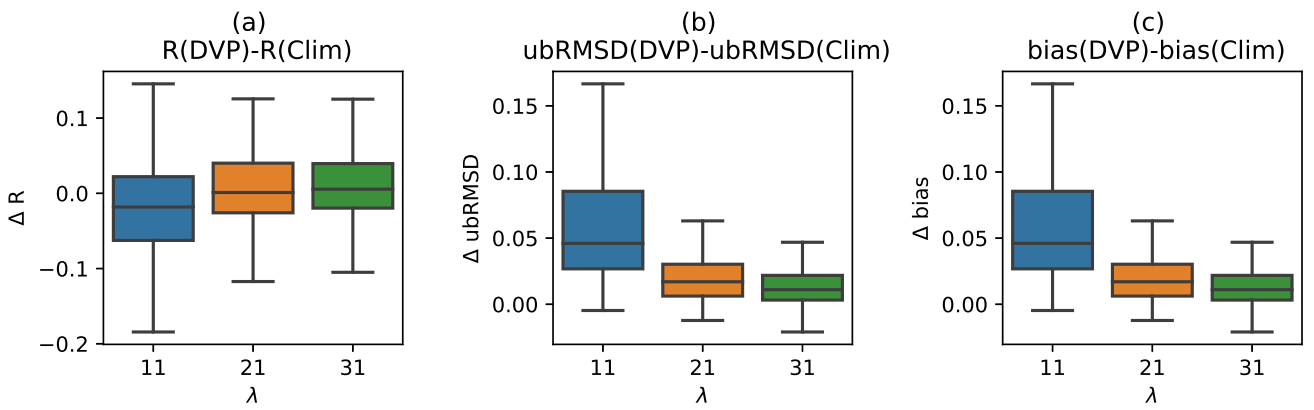

Figure 11. Box plot of the difference in (a) Pearson correlation coefficient (R), (b) unbiased RMSD and (c) bias between in situ soil moisture and soil moisture retrieved using vegetation parameters derived using dynamic vegetation parameters ( $\lambda$ on $x$-axis) and those derived from climatological values for all stations. The box extends from the lower to upper quartile values of the data, with a line at the median. The lower whisker is at the lowest datum above Q1 - $1.5 *(\mathrm{Q} 3-\mathrm{Q} 1)$ and the upper whisker at the highest datum below Q3 + 1.5* (Q3 - Q1), where Q1 and Q3 are the first and third quartiles. Outliers are omitted for clarity.

Figure 12 shows how the Pearson correlation coefficient for each kernel length compares to that from climatology for the five most prevalent cover types. A value of zero indicates performance equivalent to that obtained from climatology. Positive/negative values indicate that dynamic vegetation parameters are better/worse than climatology. In rainfed cropland $(L C=10)$, using a short window had a very detrimental effect compared to using climatological values. Increasing the kernel half-width generally improved performance. However, the results remained mixed, with the DVP yielding a modest improvement at about half of the stations. Similarly mixed results were observed in the other cover types. In grasslands ( $L C=130$ ), the results were also mixed, though increasing $\lambda$ generally resulted in an improvement. In addition to the $\mathrm{R}$ values from climatology already being high in needleleaf forest areas $(\mathrm{LC}=70)$, it is noteworthy that introducing DVPs often improved the estimate further. The influence of increasing $\lambda$ beyond 21 days in this cover type seemed limited for the stations with $R>0.5$. Results in the broadleaf forest areas were less consistent, but $\mathrm{R}$ was generally lower in this cover type. Using DVP generally led to an improvement in shrubland areas. At sites where $\mathrm{R}$ was closer to 0.5 , using DVP generally resulted in an improvement regardless of the size of $\lambda$. 
(a) LC: 10

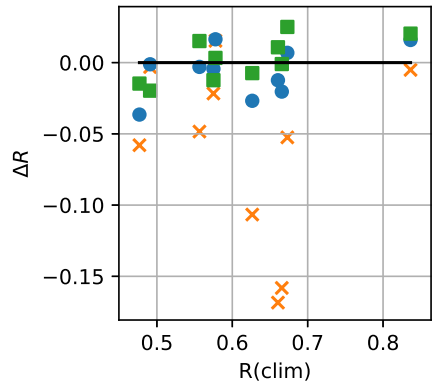

(d) LC: 120

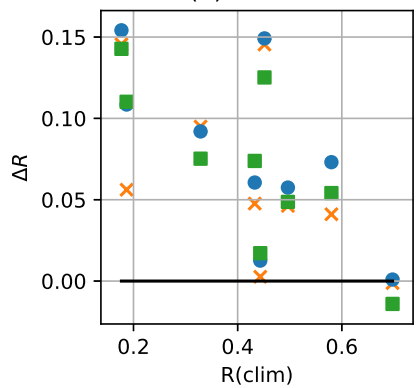

(b) LC: 61

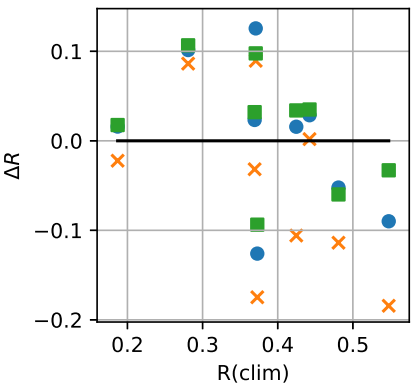

(e) LC: 130

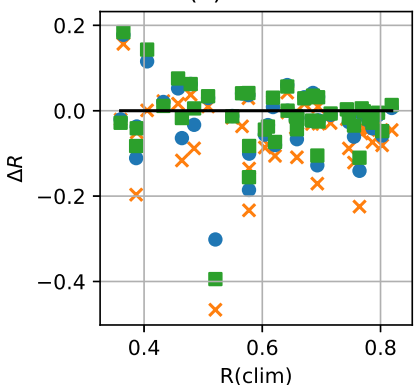

(c) LC: 70

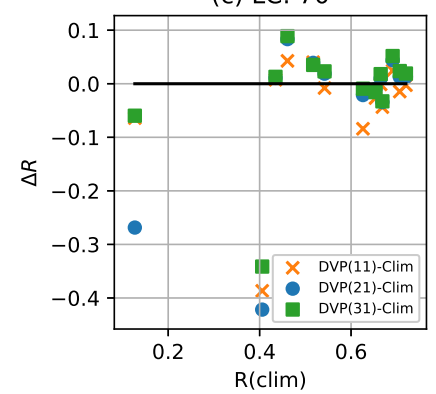

Figure 12. The influence of kernel half-width $(\lambda)$ on the Pearson correlation coefficient (R) at rainfed cropland (a), broadleaf forest (b), needleleaf forest (c), shrubland (d) and grassland (e) sites. Differences are shown with respect to the $\mathrm{R}$ based on vegetation parameters from climatology.

\section{Discussion}

Estimating dynamic vegetation parameters using a kernel smoother or similar approach can be beneficial in areas where there is interannual variation in the vegetation cover. Interannual variability may include the presence of a long-term trend, a variation in terms of the timing of the growing season or a change in the vegetation moisture content or structure. By capturing interannual variation in the slope and curvature estimates, and hence the sensitivity, the dynamic vegetation parameters are capable of accounting for this interannual variability in the soil moisture retrieval algorithm. However, the results presented here suggest that the vegetation parameters estimated using the current "climatology" approach often produce a better estimate of soil moisture than the dynamic parameters.

The slope and curvature describe how the normalized backscatter coefficient varies with incidence angle, which is an indication of the relative importance of different scattering mechanisms to the total backscatter. The relative importance of surface, volumetric and multiple scattering depends on many parameters describing the state of the soil and vegetation including the dielectric properties, roughness and texture of the soil, the vegetation water content, its distribution within the vegetation, the structure and geometry of the vegetation, as well as the presence of surface canopy water. Individual local slope values reflect the instantaneous state of the vegetation and soil. It is essential to aggregate the local slope values due to their inherently noisy nature and to ensure that a large enough range of incidence angles is sampled. However, aggregating local slope values in time also combines observations acquired at different times, and therefore affected by different states of the soil and vegetation. Using the climatology approach, the local slope values are aggregated over several years, so that short-term fluctuations are averaged out. As a result, the climatological vegetation parameters are smooth, as they primarily reflect longer-term variations due to the seasonal cycle in vegetation biomass and structure. The dynamic vegetation parameters, on the other hand, are more sensitive to short-term fluctuations. Results in Figure 9 show that increasing the kernel window length could smooth out short-term fluctuations, but is that the right thing to do?

Using a short window, the estimated slope, curvature and sensitivity are a superposition of a seasonal signal due to vegetation and higher frequency variations. These 
fluctuations are due to physical changes in the soil and vegetation state, in particular the vegetation state. The fundamental question is whether or not the vegetation parameters, as currently defined, should contain these short-term fluctuations. The detrimental impact of the DVPs on the performance of the soil moisture retrieval suggests not.

Recall that the linear relationship between slope and incidence angle is at the core of the TUW SMR. Wagner et al. [8] demonstrated this relationship using several years of ERS data and argued that averaging over several years ensured that measurement noise was suppressed to yield average slope values that represent vegetation phenology. This explains why early iterations of the TUW SMR representing the seasonal cycle with empirical trigonometric functions were successful and why the climatological vegetation parameters continue to provide a robust soil moisture retrieval. Employing a kernel to dynamically estimate vegetation parameters implicitly assumes that the relationship at shorter time scales is also primarily governed by phenology. The short-term fluctuations introduced in the slope and curvature at short kernel lengths suggest that the slope of the linear fit may vary in response to short-term variations in vegetation structure and water content changes.

To use dynamic vegetation parameters effectively, there is an urgent need for an improved understanding of the factors underlying short-term variations in the relationship between backscatter and incidence angle. From a physical perspective, this translates to a need to understand factors that influence variations in scattering mechanisms and backscatter at scales finer than the seasonal cycle. Examples include the influence of water availability and atmospheric demand on internal water content and the influence of surface water on the vegetation due to interception and dew. Tower-based L-band observations have demonstrated that short-term variations in these quantities affect total backscatter [26], though their impact on the contribution of various scattering mechanisms to total backscatter still needs to be quantified.

In terms of the TUW SMR approach, their impact on the sensitivity of total backscatter to soil moisture is of particular importance. Recall that the dry reference, or more specifically the difference between the dry and wet references, is a measure of the sensitivity to soil moisture. Variations in this sensitivity are intended to represent the attenuating effect of the vegetation on the signal backscattered from the soil. From a physical perspective, the definition of the dry reference and sensitivity could eventually be revisited to account for the influence of these short-term confounding influences on soil moisture sensitivity. However, a more pragmatic approach would be to retain the current definitions of the dry reference and sensitivity and adapt the kernel smoother implementation to ensure that the dynamic vegetation parameters used in soil moisture retrieval capture only phenologyrelated variations. This could be achieved by increasing the kernel length to smooth out the fluctuations, though this incurs a risk of smoothing out real phenological features such as those identified by Pfeil et al. [14]. Alternatively, a data-driven approach could be used to identify local slope values that deviate from the assumed linear relationship within a kernel window and filter them out prior to the application of the kernel smoother. This would ensure that the kernel smoother captures only the seasonal variations considered in the current implementation of the TUW SMR approach, but also captures any interannual variability therein.

\section{Conclusions}

Results presented here indicate that accounting for interannual variability in the effect of vegetation on sensitivity of ASCAT normalized backscatter to soil moisture could benefit soil moisture retrievals. However, the proposed approach using a kernel smoother with a kernel half-width of $\lambda=21$ days to estimate dynamic vegetation parameters was undermined by its sensitivity to short-term variations in the relationship between slope and incidence angle. These manifested as high-frequency fluctuations in the dynamic vegetation parameters superimposed on the seasonal cycle due to phenological development. Comparing results estimated with different kernel half-widths and the climatological 
values suggested that smooth dynamic vegetation parameters, capturing phenological development, produce the best soil moisture retrieval.

The success of the current TUW SMR approach, and its precursors, appears to lie in the robustness of estimating the parameters of the linear relationship between slope and incidence angle using a long data record. This ensures that the relationship effectively captures variations due to phenological change. In the DVP approach, the parameters are estimated with fewer data and are more sensitive to confounding factors that vary at finer time scales. A pragmatic approach to resolve this limitation of the proposed dynamic vegetation parameters would be to filter the local slope estimates prior to the use of the kernel smoother to ensure that local slope values influenced by unwanted confounding factors are excluded from the linear fitting in shorter time windows.

In addition to improving soil moisture retrievals, any improvement in the representation of vegetation in the TUW SMR algorithm will also benefit the ASCAT Vegetation Optical Depth (VOD) products, which are derived from the vegetation parameters estimated in the TUW SMR [27]. In the longer term, the Metop Second Generation (Metop-SG) SCA instrument is scheduled to launch in October 2024. It builds on the heritage of its predecessor ASCAT, but will also provide VH- and HH-pol data in addition to VV-pol [28]. The temporal density of data will be comparable to that from ASCAT. Additional polarizations provide complementary information on the contributions from soil and vegetation and are expected to benefit soil moisture and vegetation products. To make optimal use of the SCA data, it is essential to improve our understanding of how the incidence angle dependence of backscatter varies over shorter time scales due to soil and vegetation processes at time scales shorter than phenological development.

Author Contributions: Conceptualization, S.C.S.-D., S.H., W.W. and M.V.; data curation, S.C.S.-D. and S.H.; funding acquisition, S.C.S.-D. and W.W.; investigation, S.C.S.-D.; methodology, S.C.S.-D., S.H., W.W. and M.V.; resources, S.H. ; writing-original draft, S.C.S.-D.; writing-review and editing, S.H., W.W. and M.V. All authors read and agreed to the published version of the manuscript.

Funding: This research was funded by EUMETSAT Visiting Scientist Activity H SAF CDOP3 H AVS18 02 and the Austrian Space Application Programme (ASAP) through the DWC-Radar (No. 873658) project.

Data Availability Statement: The data used in this study are from the Metop-A ASCAT SZR Level $1 \mathrm{~b}$ data which can be downloaded from the EUMETSAT Data Centre (https:/ / eoportal.eumetsat.int, accessed on 27 February 2021).

Conflicts of Interest: The authors declare no conflict of interest.

\section{References}

1. Srivastava, P.K. Satellite Soil Moisture: Review of Theory and Applications in Water Resources. Water Resour. Manag. 2017, 31, 3161-3176. [CrossRef]

2. Entekhabi, D.; Njoku, E.G.; O’Neill, P.E.; Kellogg, K.H.; Crow, W.T.; Edelstein, W.N.; Entin, J.K.; Goodman, S.D.; Jackson, T.J.; Johnson, J.; et al. The Soil Moisture Active Passive (SMAP) Mission. Proc. IEEE 2010, 98, 704-716. [CrossRef]

3. Kerr, Y.H.; Waldteufel, P.; Wigneron, J.; Martinuzzi, J.; Font, J.; Berger, M. Soil moisture retrieval from space: The Soil Moisture and Ocean Salinity (SMOS) mission. IEEE Trans. Geosci. Remote Sens. 2001, 39, 1729-1735. [CrossRef]

4. Kerr, Y.H.; Waldteufel, P.; Wigneron, J.; Delwart, S.; Cabot, F.; Boutin, J.; Escorihuela, M.; Font, J.; Reul, N.; Gruhier, C.; et al. The SMOS Mission: New Tool for Monitoring Key Elements ofthe Global Water Cycle. Proc. IEEE 2010, 98, 666-687. [CrossRef]

5. Wagner, W.; Hahn, S.; Kidd, R.; Melzer, T.; Bartalis, Z.; Hasenauer, S.; Figa-Saldaña, J.; de Rosnay, P.; Jann, A.; Schneider, S.; et al. The ASCAT Soil Moisture Product: A Review of its Specifications, Validation Results, and Emerging Applications. Meteorol. Z. 2013, 22, 5-33. [CrossRef]

6. Brocca, L.; Crow, W.T.; Ciabatta, L.; Massari, C.; Rosnay, P.d.; Enenkel, M.; Hahn, S.; Amarnath, G.; Camici, S.; Tarpanelli, A.; et al. A Review of the Applications of ASCAT Soil Moisture Products. IEEE J. Sel. Top. Appl. Earth Obs. Remote Sens. 2017, 10, 2285-2306. [CrossRef]

7. Steele-Dunne, S.C.; McNairn, H.; Monsivais-Huertero, A.; Judge, J.; Liu, P.W.; Papathanassiou, K. Radar Remote Sensing of Agricultural Canopies: A Review. IEEE J. Sel. Top. Appl. Earth Obs. Remote Sens. 2017, 10, 2249-2273. [CrossRef]

8. Wagner, W.; Lemoine, G.; Borgeaud, M.; Rott, H. A study of vegetation cover effects on ERS scatterometer data. IEEE Trans. Geosci. Remote Sens. 1999, 37, 938-948. [CrossRef] 
9. $\quad$ Bartalis, Z.; Wagner, W.; Naeimi, V.; Hasenauer, S.; Scipal, K.; Bonekamp, H.; Figa, J.; Anderson, C. Initial soil moisture retrievals from the MetOP-A Advanced Scatterometer (ASCAT). Geophys. Res. Lett. 2007, 34. [CrossRef]

10. Naeimi, V.; Scipal, K.; Bartalis, Z.; Hasenauer, S.; Wagner, W. An Improved Soil Moisture Retrieval Algorithm for ERS and MetOP Scatterometer Observations. IEEE Trans. Geosci. Remote Sens. 2009, 47, 1999-2013. [CrossRef]

11. Hahn, S.; Reimer, C.; Vreugdenhil, M.; Melzer, T.; Wagner, W. Dynamic Characterization of the Incidence Angle Dependence of Backscatter Using MetOP ASCAT. IEEE J. Sel. Top. Appl. Earth Obs. Remote Sens. 2017, 10, 2348-2359. [CrossRef]

12. Melzer, T. Vegetation modelling in WARP 6.0. In Proceedings of the EUMETSAT Meteorological Satellite Conference, Vienna, Austria, 16-20 September 2013; pp. 16-20.

13. Steele-Dunne, S.C.; Hahn, S.; Wagner, W.; Vreugdenhil, M. Investigating vegetation water dynamics and drought using MetOP ASCAT over the North American Grasslands. Remote Sens. Environ. 2019, 224, 219-235. [CrossRef]

14. Pfeil, I.; Wagner, W.; Forkel, M.; Dorigo, W.; Vreugdenhil, M. Does ASCAT observe the spring reactivation in temperate deciduous broadleaf forests? Remote Sens. Environ. 2020, 250, 112042. [CrossRef]

15. Hahn, S.; Wagner, W.; Steele-Dunne, S.C.; Vreugdenhil, M.; Melzer, T. Improving ASCAT Soil Moisture Retrievals With an Enhanced Spatially Variable Vegetation Parameterization. IEEE Trans. Geosci. Remote Sens. 2020, 1-16. [CrossRef]

16. Vreugdenhil, M.; Dorigo, W.A.; Wagner, W.; De Jeu, R.A.; Hahn, S.; Van Marle, M.J. Analyzing the Vegetation Parameterization in the TU-Wien ASCAT Soil Moisture Retrieval. IEEE Trans. Geosci. Remote Sens. 2016, 54, 3513-3531. [CrossRef]

17. Wagner, W.; Noll, J.; Borgeaud, M.; Rott, H. Monitoring soil moisture over the Canadian Prairies with the ERS scatterometer. IEEE Trans. Geosci. Remote Sens. 1999, 37, 206-216. [CrossRef]

18. EUMETSAT H SAF. Available online: http://hsaf.meteoam.it/ (accessed on 1 December 2020).

19. Wagner, W.; Lemoine, G.; Rott, H. A Method for Estimating Soil Moisture from ERS Scatterometer and Soil Data. Remote Sens. Environ. 1999, 70, 191-207. [CrossRef]

20. Hastie, T.; Tibshirani, R.; Friedman, J. The Elements of Statistical Learning: Data Mining, Inference, and Prediction; Springer Science \& Business Media: Berlin, Germany, 2009.

21. Bell, J.E.; Palecki, M.A.; Baker, C.B.; Collins, W.G.; Lawrimore, J.H.; Leeper, R.D.; Hall, M.E.; Kochendorfer, J.; Meyers, T.P.; Wilson, T.; et al. U.S. Climate Reference Network Soil Moisture and Temperature Observations. J. Hydrometeorol. 2013, 14, 977-988. [CrossRef]

22. Dorigo, W.A.; Wagner, W.; Hohensinn, R.; Hahn, S.; Paulik, C.; Xaver, A.; Gruber, A.; Drusch, M.; Mecklenburg, S.; van Oevelen, P.; et al. The International Soil Moisture Network: A data hosting facility for global in situ soil moisture measurements. Hydrol. Earth Syst. Sci. 2011, 15, 1675-1698. [CrossRef]

23. Morrison, K.; Wagner, W. Explaining Anomalies in SAR and Scatterometer Soil Moisture Retrievals From Dry Soils with Subsurface Scattering. IEEE Trans. Geosci. Remote Sens. 2020, 58, 2190-2197. [CrossRef]

24. Bartalis, Z.; Scipal, K.; Wagner, W. Azimuthal anisotropy of scatterometer measurements over land. IEEE Trans. Geosci. Remote Sens. 2006, 44, 2083-2092. [CrossRef]

25. Entekhabi, D.; Reichle, R.H.; Koster, R.D.; Crow, W.T. Performance Metrics for Soil Moisture Retrievals and Application Requirements. J. Hydrometeorol. 2010, 11, 832-840. [CrossRef]

26. Vermunt, P.C.; Khabbazan, S.; Steele-Dunne, S.C.; Judge, J.; Monsivais-Huertero, A.; Guerriero, L.; Liu, P.W. Response of Subdaily L-Band Backscatter to Internal and Surface Canopy Water Dynamics. IEEE Trans. Geosci. Remote Sens. 2020. [CrossRef]

27. Vreugdenhil, M.; Hahn, S.; Melzer, T.; Bauer-Marschallinger, B.; Reimer, C.; Dorigo, W.A.; Wagner, W. Assessing Vegetation Dynamics Over Mainland Australia With MetOP ASCAT. IEEE J. Sel. Top. Appl. Earth Obs. Remote Sens. 2017, 10, $2240-2248$. [CrossRef]

28. Stoffelen, A.; Aaboe, S.; Calvet, J.C.; Cotton, J.; Chiara, G.D.; Saldaña, J.F.; Mouche, A.A.; Portabella, M.; Scipal, K.; Wagner, W. Scientific Developments and the EPS-SG Scatterometer. IEEE J. Sel. Top. Appl. Earth Obs. Remote Sens. 2017, 10, $2086-2097$. [CrossRef] 